\title{
Studi Numerik: Pengaruh Omni-Directional Guide Vane (ODGV) Terhadap Efisiensi Turbin Angin Savonius Konvensional
}

\author{
Yoga Arob Wicaksono \\ Teknik Mesin, Universitas Muhammadiyah Ponorogo \\ J1. Budi Utomo No. 10 Ponorogo \\ E-mail: yoga_arob@umpo.ac.id
}

\begin{abstract}
Abstrak
Penelitian ini menyajikan analisa numerik pengaruh Omni-Direction Guide Vane (ODGV) terhadap efisiensi turbin angin Savonius konvensional. Tujuan utama dari penelitian ini adalah untuk mengembangkan desain ODGV yang dapat meningkatkan efisiensi turbin angin Savonius skala kecil. Tiga desain ODGV dengan sudut kemiringan $50^{\circ}, 60^{\circ}$, dan $70^{\circ}$ dianalisa menggunakan software ANSYS-Fluent R15. Simulasi dilakukan pada model 2D dengan model turbulen $k-\varepsilon$ standar dan kecepatan angin konstan $6 \mathrm{~m} / \mathrm{s}$. Parameter efisiensi yang dihitung pada simulasi ini antara lain: torque coefficient $\left(C_{\mathrm{t}}\right)$, power coefficient $\left(C_{\mathrm{p}}\right)$, dan tip speed ratio (TSR). Hasil penelitian menunjukkan bahwa OGDV mampu meningkatkan efisiensi turbin angin Savonius sebesar 82\%. Peningkatan tertinggi dicapai dengan menggunakan variasi ODGV dengan sudut kemiringan $50^{\circ}$.
\end{abstract}

Diterima: 21-07-2020; Direvisi: 24-08-2020; Dipublikasi: 01-09-2020

Kata kunci: CFD; efisiensi; OGDV; turbin angin Savonius

\begin{abstract}
This research presents a numerical analysis of the effect of Omni-Direction Guide Vane (ODGV) on the efficiency of Savonius wind turbines. The main objective of this research is to develop an ODGV design that can improve the efficiency of small-scale Savonius wind turbines. Three ODGV designs with inclination angles of $50^{\circ}, 60^{\circ}$, and $70^{\circ}$ were analyzed using ANSYS-Fluent R15 software. Simulations performed on the 2D model with the turbulent model $k$ $\varepsilon$ at constant wind speed of $6 \mathrm{~m} / \mathrm{s}$. The efficiency parameters calculated in this simulation include: torque coefficient $\left(C_{\mathrm{t}}\right)$, power coefficient $\left(C_{\mathrm{p}}\right)$, and tip speed ratio (TSR). The results show that OGDV can increase the efficiency of Savonius wind turbines by $82 \%$. The highest increase was achieved using variations of ODGV with a tilt angle of $50^{\circ}$.
\end{abstract}

Keywords: CFD; efficiency; OGDV; Savonius wind turbine

\section{Pendahuluan}

Turbin angin dapat dimanfaatkan untuk mengonversi energi angin ke energi listrik. Kajian potensi energi angin di suatu daerah perlu dilakukan karena menjadi syarat penting agar turbin angin beroperasi dengan optimal. Kecepatan angin di Indonesia berkisar antara 2 sampai $6 \mathrm{~m} / \mathrm{s}$. Sehingga generator energi angin yang dapat digunakan mulai skala kecil $(10 \mathrm{~kW})$ sampai medium $(10-100 \mathrm{~kW})$. Nominal kapasitas pembangkit listrik tenaga angin di Indonesia sebesar 1,06 MW dari total pembangkit listrik pada tahun 2009 [1]. Turbin angin dapat menjadi alternatif untuk mengurangi beban listrik di lingkungan perkotaan. Lingkungan perkotaan membutuhkan energi listrik lebih banyak dan umumnya memiliki gedung tinggi/high rise building yang banyak, sehingga menjadi pilihan menarik untuk penempatan turbin angin [2]. Turbin angin yang diletakkan di gedung tinggi semakin diminati sebagai bagian dari teknologi yang sesuai untuk aplikasi pembangkit mikro. Namun, lingkungan perkotaan umumnya memiliki masalah kecepatan angin yang rendah dan sering terjadi turbulensi [3]. Selain itu kecepatan angin selalu berubah dan arahnya tidak selalu sama [4].

Untuk menyesuaikan karakteristik angin di lingkungan perkotaan, maka dapat dipilih turbin sumbu vertikal tipe Savonius. Tipe turbin tersebut menjadi pilihan yang tepat karea sesuai dengan karakteristik angin di lingkungan perkotaan dan mudah dibuat. Beberapa kelebihan turbin angin Savonius antara lain: mampu beroperasi pada kondisi angin yang turbulen dan fluktuatif pada lingkungan perkotaan [5]. Namun turbin Savonius memiliki kekurangan efisiensi yang lebih rendah dibanding turbin jenis lain [6]. Penelitian-penelitian sebelumnya rata-rata mendapatkan koefisien power turbin Savonius antara 0,10-0,25 [5]. Untuk meningkatkan efisiensi beberapa peneliti melakukan penambahan perangkat di 
sekitar turbin angin vertikal, contohnya plat deflektor sederhana. Penambahan plat deflektor pada prinsipnya mengurangi torsi negatif yang terjadi pada salah satu sudu, sehingga torsi total turbin meningkat [7]. Namun plat deflektor sederhana tidak dapat menerima angin dari segala arah, sedangkan kondisi angin di lingkungan perkotaan umumnya mengalami turbulensi. Altan mendesain sebuah plat deflektor yang dipasang pada turbin Savonius [8]. Namun desain tersebut memiliki kekurangan, yaitu plat deflektor hanya menerima angin dari satu arah saja. Beberapa percobaan untuk mengaplikasikan turbin angin di atas bangunan gedung telah dilakukan, namun performanya kecil [9]. Sehingga untuk mengatasi masalah tersebut dikembangkan perangkat lain, yaitu Omni Directional Guide Vane (ODGV). ODGV memiliki kemampuan menerima angin dari segala arah disamping meningkatkan efisiensi turbin.

Beberapa penelitian sebelumnya menyelidiki pengaruh ODGV terhadap efisiensi pada beberapa jenis turbin angin vertikal. Variabel-variabel yang membedakan desain ODGV dari berbagai penelitian antara lain: profil sudu, sudut, jumlah, dan dimensi guide vane. Untuk memprediksi pengaruh ODGV terhadap turbin angin vertikal, penelitianpenelitian sebelumnya menggunakan software Computational Fluid Dynamics (CFD). Penggunaan simulasi CFD, dapat dilakukan simulasi yang tidak terbatas, analisa dan optimasi tanpa membuat konstruksi dari beberapa turbin dengan konfigurasi geometri berbeda. Dengan simulasi CFD pula, koefisien torsi, power dan tekanan pada rotor dapat diprediksi [4].

Sebuah model turbin angin vertikal Zephyr dikembangkan dengan menambahkan omni directional stator vane. Stator yang digunakan berjumlah 9 buah tersusun secara menyebar $360^{\circ}$ di sekitar rotor turbin. Sedangkan profil stator menggunakan plat yang diberi tambahan winglet pada ujungnya. Rotor turbin yang digunakan merupakan pengembangan dari rotor turbin Savonius. Jumlah sudu turbin sebanyak 5 sudu dan didesain memiliki overlap. Studi numerik menggunakan software Fluent 6.3.26 secara 3D dengan model turbulen k- $\varepsilon$ untuk melakukan simulasi transien. Kemudian dilakukan eksperimen untuk menentukan performa operasi dari turbin [4].

Sebuah rancangan ODGV dikembangkan oleh W.T. Chong dan diintegrasikan dengan turbin angin vertikal tipe Hrotor. Guide vane yang digunakan berjumlah 4 pasang dengan profil plat rata yang diletakkan pada kerucut pada bagian atas dan bawahnya. Masing-masing pasangan guide vane memiliki sudut $20^{\circ}$ dan $55^{\circ}$. Rotor turbin yang digunakan menggunakan profil airfoil Wortmann FX63-137 sejumlah 5 sudu. Penelitian dilakukan secara eksperimen pada wind tunnel dan numerik menggunakan software Fluent 6.3. Pada pengujian eksperimen wind tunnel digunakan variasi arah angin pada arah $0^{\circ}, 30^{\circ}$ dan $60^{\circ}$. Hasil pengujian wind tunnel, ODGV mampu meningkatkan kecepatan rotasi rotor turbin sebesar 182\% pada kecepatan angin $6 \mathrm{~m} / \mathrm{s}$. Dengan aplikasi beban, turbin dengan ODGV berotasi stabil pada putaran 144 rpm dengan torsi maksimum sebesar 23,64 mN.m dan menghasilkan daya luaran sebesar 0,4352 W. Dengan demikian rasio augmentasi (dengan ODGV terhadap tanpa ODGV) sebesar 1,87 kali pada RPM dan 3,48 kali pada daya [10].

Model ODGV selanjutnya dikembangkan oleh Nobile dengan mengintegrasikan stator vane dan turbin angin Daerius. Stator vane yang digunakan memakai profil airfoil NACA 0018 sejumlah 8 sudu. Stator vane disusun vertikal di sekitar turbin dan dipasang pada permukaan kerucut di bagian atas dan bawah. Sedangkan jumlah rotor Daerius yang digunakan sebanyak tiga sudu dan memiliki profil airfoil NACA 0018. Hasil simulasi yang dilakukan dengan software ANSYS CFX secara 2D menunjukkan koefisien torsi turbin angin Daerius meningkat sebesar 30-35\% dibandingkan tanpa stator [11].

Pada penelitian ini akan dibuat ODGV model sederhana. Beberapa variabel yang membedakan dengan desain pada penelitian sebelumnya antara lain: tata letak sudu, sudut kemiringan, dan dimensi guide vane. Tata letak dan jumlah disusun menyebar mengelilingi turbin sejumlah 8 sudu. Profil sudu menggunakan plat rata yang disusun secara vertikal. Desain penopang sudu menggunakan plat dengan permukaan rata. Dimensi ODGV disesuaikan dengan ukuran turbin. Rotor turbin yang digunakan menggunakan rotor turbin Savonius konvensional. Konfigurasi rotor turbin Savonius 
Yoga Arob Wicaksono/Jurnal Rekayasa Mesin

p-ISSN: 1411-6863, e-ISSN: 2540-7678

Vol.15|No.2|82-88|Agustus|2020

mengacu referensi yang disarankan oleh [5]. Tujuan dari penelitian ini adalah untuk menyelidiki pengaruh variasi sudut ODGV terhadap performa turbin angin Savonius. Untuk memprediksi performa turbin angin pada penelitian ini digunakan metode simulasi CFD. Simulasi dilakukan dengan model 2 dimensi untuk menghemat waktu simulasi. Variasi ODGV yang dibuat sebanyak 3 variasi dengan sudut kemiringan yang berbeda, yaitu $50^{\circ}, 60^{\circ}$ dan $70^{\circ}$.

\section{Material dan metodologi}

Pada penelitian ini simulasi dilakukan dengan model 2D. Software yang digunakan adalah Ansys-Fluent R14.5. Berdasarkan penelitian terdahulu, model turbulen $k-\varepsilon$ standar dan $k-\varepsilon$ SST memiliki akurasi yang tinggi [12]. Sehingga pada simulasi ini yang dipilih adalah model turbulen $k-\varepsilon$ SST. Kecepatan angin dibuat konstan pada $6 \mathrm{~m} / \mathrm{s}$ disesuaikan dengan kecepatan angin rata-rata tertinggi di wilayah Indonesia [1]. Model OGDV mengacu pada desain Chong. Desain OGGV dibuat sejumlah 3 variasi dengan membedakan sudut kemiringan sudu pengarah antara lain, $50^{\circ}, 60^{\circ}$ dan $70^{\circ}$. Sedangkan model turbin angin Savonius menggunakan model tipe S konvensional.

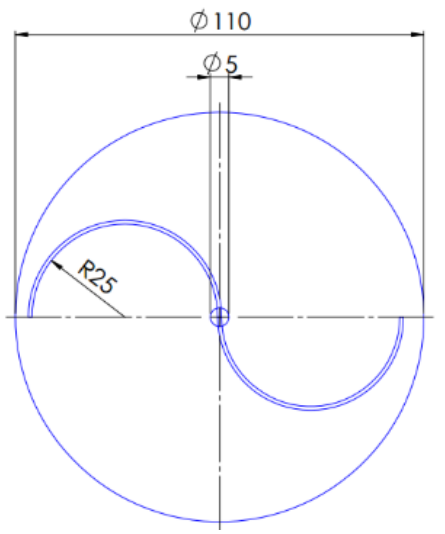

Gambar 1. Geometri 2D turbin Savonius
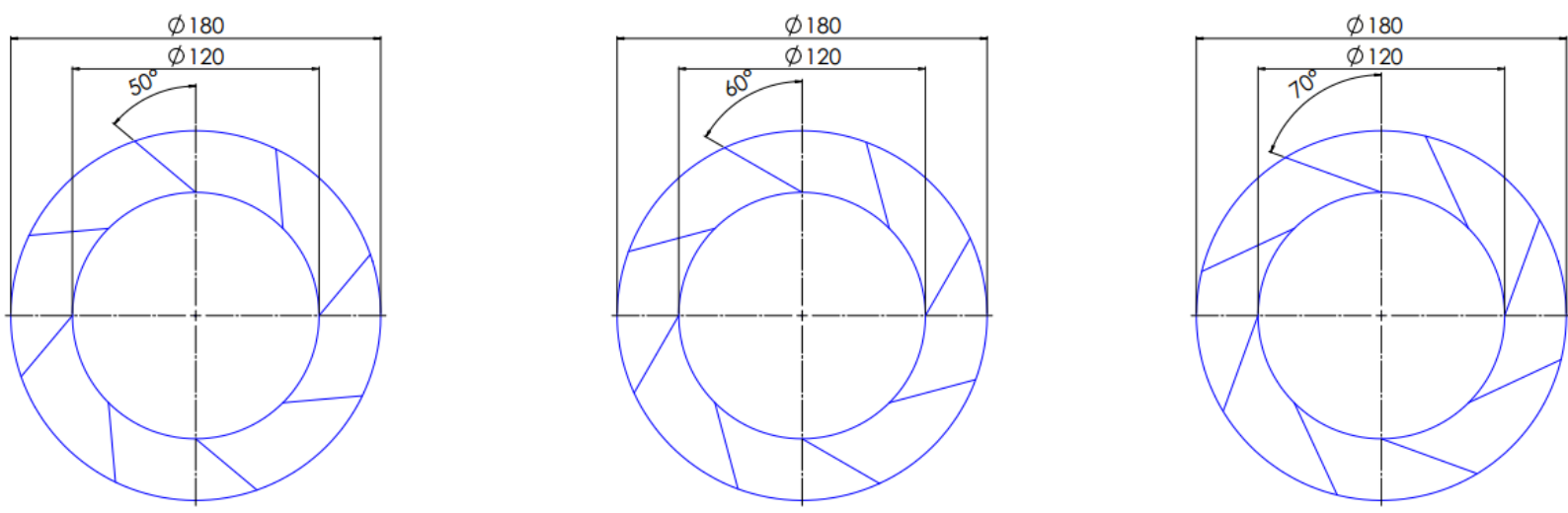

Gambar 2. Geometri ODGV (a) Variasi 1, (b) Variasi 2, (c) Variasi 3

Domain komputasi yang dipilih pada penelitian ini adalah bagian dari seksi uji wind tunnel dengan dimensi sebagai berikut: panjang $10 \mathrm{~m}$ dan lebar $5 \mathrm{~m}$. Model OGDV dan turbin angin diletakkan pada jarak 2,5 meter dari inlet dan 2,5 m dari wall symetry seksi uji seperti pada hambar berikut ini: 
Yoga Arob Wicaksono/Jurnal Rekayasa Mesin

p-ISSN: 1411-6863, e-ISSN: 2540-7678

Vol.15|No.2|82-88|Agustus|2020

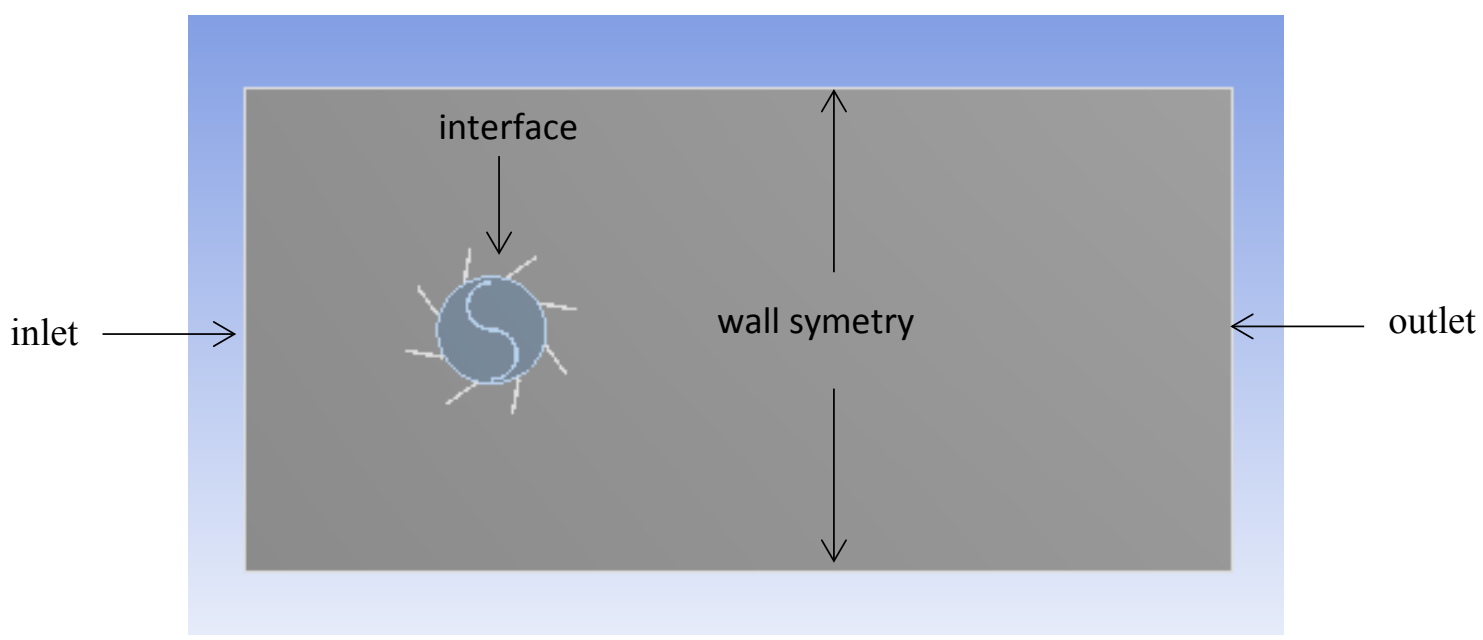

Gambar 3. Domain komputasi

Setelah pemodelan secara geometri, selanjutnya adalah pemodelan kondisi fisik yang mewakili kondisi nyata atau kondisi kerja yang diinginkan. Jenis aliran adalah internal flow dimana fluida bekerja di dalam ruangan melewati ODGV dan turbin Savonius. Domain komputasi selanjutnya dibuat mesh, yaitu dengan membagi dalam elemen-elemen kecil yang nantinya berperan sebagai kontrol surface atau volume data perhitungan. Model mesh yang digunakan adalah model mesh hybrid dengan bentuk segitiga. Berikut ini adalah penampakan hasil meshing hybrid dengan dimensi mesh terkecil sebesar 0,001 m. Rotating grid digunakan untuk menghitung bidang aliran yang dihasilkan oleh VAWT. Rotating grid ditempatkan di dalam grid stasioner(tidak berputar) dan terhubung ke turbin [13].

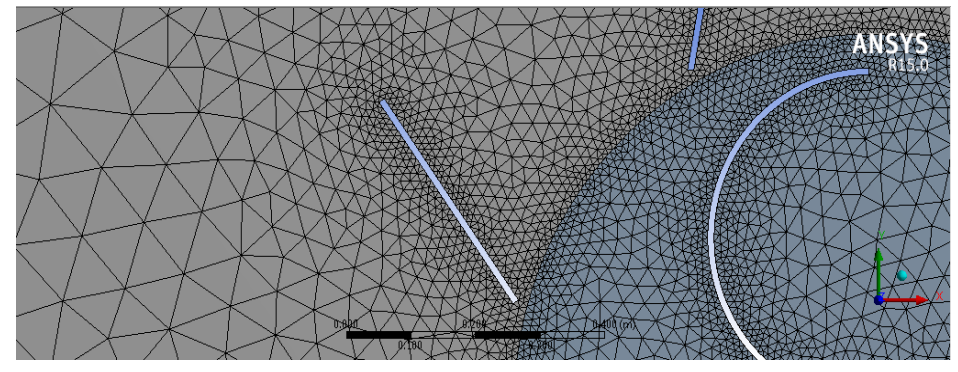

Gambar 4. Meshing

Berikutnya kondisi batas pada simulasi ini adalah sebagai berikut:

Tabel 1. Kondsi batas simulasi

\begin{tabular}{ll}
\hline Density & $1,225 \mathrm{~kg} / \mathrm{m}^{3}$ \\
Viscosity & $1,778 \times 10^{-5} \mathrm{~kg} / \mathrm{m} . \mathrm{s}$ \\
Pressure & $101325 \mathrm{~Pa}$ \\
Temperature & $303.3 \mathrm{~K}$ \\
Inlet velocity & $6 \mathrm{~m} / \mathrm{s}$ \\
Outlet pressure & $0 \mathrm{~Pa}$ \\
\hline
\end{tabular}

Kriteria konvergensi diatur pada $10^{-5}$ untuk mencapai hasil data yang stabil. Setelah simulasi selesai dilakukan perhitungan data meliputi persamaan $C_{\mathrm{t}}, C_{\mathrm{p}}$ dan TSR dengan Persamaan (1-3) sebagai berikut:

$$
C_{T}=\frac{2 T_{T}}{\rho_{a} A_{T} V^{2} R}
$$




$$
C_{p}=\frac{2 P_{T}}{\rho_{a} A_{T} V^{3}}
$$

$$
\lambda=\frac{2 \pi N R}{60 V}
$$

dimana T, $\rho, A, V, P, N$ dan $R$, adalah torsi aktual, densitas udara, luas sapuan bagian depan turbin, kecepatan aliran udara, daya aktual, putaran poros turbin dan jari-jari turbin.

\section{Hasil dan pembahasan}

Untuk mendapatkan karakteristik performa dari tiga variasi model OGDV dan pengaruhnya terhadap performa turbin angin savonius, maka dilakukan simulasi pada software ANSYS Fluent R15. Simulasi dilakukan pada TSR 0,1 sampai 0,7 pada kecepatan angin kontan $6 \mathrm{~m} / \mathrm{s}$. Gambar 5 (a) dan (b) dibawah menunjukan perbandingan nilai $C_{\mathrm{t}}$ dan $C_{\mathrm{p}}$ pada tiga variasi ODGV dan turbin Savonius tanpa ODGV. Pada turbin angin tanpa ODGV $\mathrm{C}_{\mathrm{t}}$ tertinggi dicapai pada TSR 0,7 yaitu sebesar 0,037 . Sedangkan $C_{\mathrm{p}}$ tertinggi dicapai pada TSR 0,7 sebesar 0,015 . Efisiensi turbin Savonius sangat rendah terbukti pada hasil simulasi ini. Hal ini disebabkan karena karakteristik kerja dari turbin angin Savonius sendiri. Turbin angin Savonius adalah turbin angin tipe vertikal yang memanfaatkan gaya hambat angin. Turbin angin Savonius menggunakan 2 sudu cekung saling berlawaan untuk menangkap energi angin. Pada saat sudu cekung menangkap angin maka energi angin dikonversi menjadi torsi positif pada poros. Namun pada sisi berlawanan, sudu yang membelakangi angin menerima energi dari angin juga sehingga menimbulkan torsi negatif pada poros turbin. Untuk mengurangi torsi negatif ini perlu ditambahkan perangkat berupa ODGV. Pada grafik ODGV 50, $C_{\mathrm{t}}$ tertinggi dicapai pada TSR 0,5 sebesar 0,24. Sedangkan $C_{\mathrm{p}}$ tertinggi dicapai pada TSR 0,7 sebesar 0,0882. Hasil ini membuktikan bahwa ODGV meningkatkan efisiensi turbin angin Savonius sebesar $83 \%$.

Selanjutnya pada grafik ODGV $60, C_{\mathrm{t}}$ paling tinggi dicapai pada TSR 0,5 sebesar 0,132 . Sedangkan $C_{\mathrm{p}}$ paling tinggi dicapai pada TSR 0,7 sebesar 0,023. Hasil tersebut menunjukkan bahwa turbin Savonius dengan ODGV 60 mengalami penurunan efisiensi jika dibandingkan dengan menggunakan ODGV 50. Hal ini disebabkan karena desain ODGV 60 memiliki sudut kemiringan guide vane yang lebih besar $\left(60^{\circ}\right)$, sehingga timbul pressure drop yang tinggi pada saluran ODGV karena angin dibelokkan dengan sudut yang lebih tajam oleh guide vane.

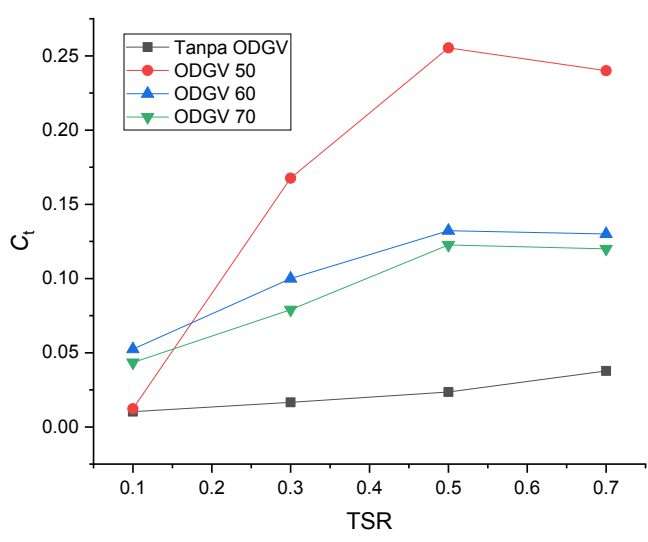

(a)

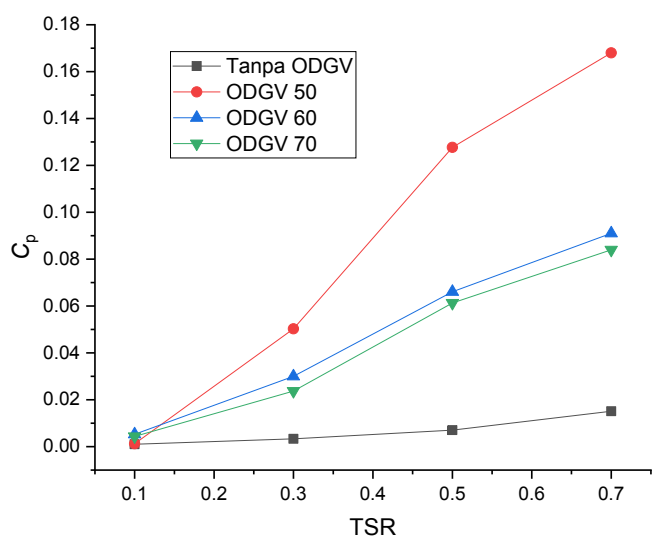

(b)

Gambar 5. (a) Grafik $C_{\mathrm{t}}$ terhadap TSR (b) Grafik $C_{\mathrm{p}}$ terhadap TSR 
Yoga Arob Wicaksono/Jurnal Rekayasa Mesin p-ISSN: 1411-6863, e-ISSN: 2540-7678

Vol.15|No.2|82-88|Agustus|2020

Pada grafik ODGV $70 C_{\mathrm{t}}$ maksimal dicapai pada TSR 0,5 sebesar 0,0123. Sedangkan $\mathrm{C}_{\mathrm{p}}$ tertinggi dicapai pada TSR 0,7 sebesar 0,048 . Grafik $C_{\mathrm{p}}$ dan $C_{\mathrm{t}}$ mengalami penurunan signifikan dibanding dua variasi ODGV lainnya. Penurunan efisiensi turbin angin Savonius dengan ODGV 70 disebabkan karena sudut kemiringan guide vane yang ekstrim, yaitu $70^{\circ}$. Aliran angin yang masuk ke ODGV dibelokkan secara paksa oleh guide vane pada sudut yang ekstrim, sehingga menghambat laju aliran udara kemudian timbul pressure drop yang lebih besar di saluran ODGV. Dengan demikian dapat disimpulkan bahwa, khusus untuk turbin angin Savonius, semakin besar sudut ODGV, maka semakin tidak efektif untuk meningkatkan efisiensi.

Turbin angin Savonius konvensional menerima aliran angin secara efektif dari arah tegak lurus sumbu. Sehingga tidak membutuhkan ODGV dengan sudut kemiringan guide vane yang ekstrim. ODGV berperan sebagai perangkat pelindung pada bagian sudu cekung, maka bisa meminimalisir gaya hambat pada bagian sudu cembung dan berdampak pada pengurangan torsi negatif pada poros turbin [14]. Pembelokan aliran udara dan efek throttling pada perangkat seperti guide vane, mampu meningkatkan kecepatan anguler turbin angin sumbu vertikal yang mengarah ke peningkatan daya mekanis turbin [15].

\section{Kesimpulan}

Konsep turbin angin Savonius sangat mudah diaplikasikan untuk sistem pembangkit tenaga listrik skala kecil. Namun efisiensinya rendah sehingga membutuhkan modifikasi untuk menigkatkan performanya. Dengan perhitungan numerik, penambahan perangkat berupa ODGV terbukti mampu meningkatkan efisiensi turbin sebesar $82 \%$ dibadingkan tanpa menggunakan ODGV. Namun pemilihan sudut ODGV yang terbaik perlu dilakukan untuk mendapatkan nilai efisiensi terbaik. ODGV dengan sudut kemiringan 50 mampu meningkatkan nilai $C_{\mathrm{t}}$ dan $C_{\mathrm{p}}$ turbin angin Savonius. Untuk penelitian selanjutnya perlu dilakukan studi eksperimental untuk digunakan sebagai validasi hasil perhitungan efisiensi turbin angin Savonius secara numerik.

\section{Daftar Pustaka}

[1] Hasan, M.H., Muzammil, W. K., Mahlia, T.M.I., Jannifar, A., Hasanuddin, I. A review on the pattern of electricity generation and emission in Indonesia from 1987 to 2009," Renew. Sustain. Energy Rev. 2012. Vol. 16, no. 5, pp. 3206-3219.

[2] Chong W.T. Performance investigation of a power augmented vertical axis wind turbine for urban high-rise application q. Renew. Energy, 2013. vol. 51, pp. 388-397.

[3] Walker S.L, Building mounted wind turbines and their suitability for the urban scale - A review of methods of estimating urban wind resource. Energy Build., 2011. vol. 43, no. 8, pp. 1852-1862.

[4] Pope. K. Effects of stator vanes on power coefficients of a zephyr vertical axis wind turbine. Renew. Energy, 2010. vol. 35, no. 5, pp. 1043-1051.

[5] Ricci, R., Romagnoli, R., Montelpare, S., Vitali, D. Experimental study on a Savonius wind rotor for street lighting systems q, Appl. Energy, 2016. vol. 161, pp. 143-152.

[6] Soo, K., J. Ik, Pan, J., Ryu, K. Effects of end plates with various shapes and sizes on helical Savonius wind turbines. Renew. Energy, 2015 vol. 79, pp. 167-176.

[7] Mohamed, M.H., Janiga,G., Pap, E., Thévenin, D. Optimal blade shape of a modified Savonius turbine using an obstacle shielding the returning blade. Energy Convers. Manag., 2011. vol. 52, no. 1, pp. 236-242.

[8] Altan, B.D., Atilgan,M. The use of a curtain design to increase the performance level of a Savonius wind rotors. 
Renew. Energy, 2010. vol. 35, no. 4, pp. 821-829.

[9] Krishnan, A., Paraschivoiu, M. 3D analysis of building mounted VAWT with diffuser shaped shroud. Sustain. Cities Soc.2015.

[10] Chong, W.T., Fazlizan, A., Poh, S.C., Pan, K.C., Hew, W.P., Hsiao, F.B., The design , simulation and testing of an urban vertical axis wind turbine with the omni-direction-guide-vane q. Appl. Energy, 2013. vol. 112, pp. 601-609.

[11] Nobile, R., Vahdati, M., Barlow, J.F. Unsteady flow simulation of a vertical axis wind turbine : a two-dimensional study. 2013. no. July, pp. 1-10.

[12] Maeda, T., Kamada, Y., Murata, J., Kawabata, T. Wind tunnel and numerical study of a straight-bladed vertical axis wind turbine in three-dimensional analysis (Part I : For predicting aerodynamic loads and performance). Energy, 2016. vol. 106, pp. 443-452.

[13] Trivellato, F., Raciti Castelli, M. On the Courant-Friedrichs-Lewy criterion of rotating grids in 2D vertical-axis wind turbine analysis. Renew. Energy. 2014. vol. 62, pp. 53-62.

[14] Wicaksono Y.A., Tjahjana, D. D. D. P. Computational study: The influence of omni-directional guide vane on the flow pattern characteristic around Savonius wind turbine. AIP Conf. Proc., 2017. Januari. vol. 1788.

[15] Korprasertsak, N., Leephakpreeda, T. CFD-Based Power Analysis on Low Speed Vertical Axis Wind Turbines with Wind Boosters, Elsevier B.V. 2015. vol. 79. 